\title{
Evaluation of Diagnostic Efficacy of Digital Subtraction Radiography in the Diagnosis of Simulated External Root Resorption: An in Vitro Study
}

\author{
Nasim Mokhtari Goorabjavari'1, Ahmadreza Talaeipour ${ }^{2}$, Fatemeh Ezoddini-Ardakani ${ }^{3}$, \\ Yaser Safi $^{4 *}$, Nafiseh Shamloo ${ }^{5}$ \\ ${ }^{1}$ Department of Oral and Maxillofacial Radiology, Faculty of Dentistry, Hormozgan University of Medical \\ Sciences, Bandar Abbas, Iran \\ ${ }^{2}$ Department of Oral and Maxillofacial Radiology, Faculty of Dentistry, Azad University, Tehran, Iran \\ ${ }^{3}$ Department of Oral and Maxillofacial Radiology, Faculty of Dentistry, Shahid Sadoughi University of Medical \\ Sciences, Yazd, Iran \\ ${ }^{4}$ Department of Oral and Maxillofacial Radiology, Faculty of Dentistry, Shahid Beheshti University of Medical \\ Sciences, Tehran, Iran \\ ${ }^{5}$ Department of Oral Pathology, Faculty of Dentistry, Shahid Beheshti University of Medical Sciences, Tehran, \\ Iran \\ Email: ${ }^{*}$ Yaser_safi@yahoo.com
}

Received 11 March 2015; accepted 13 April 2015; published 15 April 2015

Copyright (C) 2015 by authors and Scientific Research Publishing Inc.

This work is licensed under the Creative Commons Attribution International License (CC BY). http://creativecommons.org/licenses/by/4.0/

(c) (i) Open Access

\section{Abstract}

External root resorption can induce the degeneration of dental cementum and dentine and may extend towards the pulp reductive. Digital subtraction radiography can function as a useful tool in diagnosing degenerative carious lesions. This study investigated the diagnostic value of digital subtraction radiography in detecting external root resorption. This was a descriptive study conducted using the lab trial method. Artificially-induced external root resorption was created in different sizes at the coronal and apical aspects of 20 premolar teeth. Digital radiographs were obtained of each tooth under standard conditions and these radiographs were subtracted by imaging devices. The subtracted images and the digital radiographs were observed by three radiologists. Chi-square, Kappa test, and Z-test were used to analyze the data. The mean of general sensitivity of digital subtraction radiography and direct digital radiography was low in diagnosing $0.05 \mathrm{~mm}$ lesions $($ Sen $=35 \%$ ), yet, the accuracy index was good for all lesions (Acc $\geq 65 \%$ ). Other diagnostic parameters were also acceptable. Both types of radiography worked better in diagnosing coronal

\footnotetext{
"Corresponding author.
} 
than apical lesions $(P>0.05)$. The interpreters (observers) showed a better performance in diagnosing external root resorption using digital subtraction radiography compared to digital radiography. Both modalities were exact and accurate in detecting $0.05 \mathrm{~mm}$ lesions as well as other lesions. However, the results of digital subtraction radiography were not significantly different from those of direct digital radiography.

\title{
Keywords
}

\author{
Subtraction Radiography, Radiography, Direct Digital Radiography, External Root Resorption
}

\section{Introduction}

Dental root resorption is one of the dental problems occurring at either external or internal root sufaces. External resorption begins at the periodontal tissue leading to degeneration of cementum and dentine. If the early lesion is detected promptly, the chances of maintaining the tooth will increase. External root resorption is an irreversible multifactorial pathologic condition which can potentially lead to total loss of tooth [1] [2]. The highest incidence rate of external root resorption has been reported to occur in the incisors, yet, it has also occurred in the posterior teeth and its primary diagnosis is done through intra-oral film radiography [3] [4]. The most common sites of external root resorption are the apical and cervical regions [5].

Due to shortcomings of conventioal film radiography, the experts have been encouraged to adopt more comprehensive modalities of imaging [5]. Nowadays, digital radiography is preferred to conventional radiography [6]-[9]. The application of digital radiography is done through both direct and indirect methods in dentistry. To create a subtraction image, a radiograph is recorded of the desired region first. This image is saved on the computer with a certain pixel resolution and a specific file format. The second image obtained after applying the desired changes in the target region, should be obtained with the same geometric specificitys as the first image and be consistent with it regarding resolution and format. In this case, the subtraction of the pixels that are the same, produces a gray background. The regions undergoing changes appear as white patches (in the case of increasing density as bone gain) and dark patches (in the case of decreasing density as in bone loss) [10] [11]. Digital subtraction can display slight and minute changes in tissues created due to diagnostic and therapeutic processes or disease course and which are not detectable via conventional radiography. In fact, digital subtraction can display mineral resorption of $1 \%$ - 5\% per unit [12] [13]. Digital subtraction radiography (DSR) is used in assessing the rate of the effectiveness of drugs in the progress and treatment of periodontal diseases [14], diagnosis of the recurrence of caries beneath restorations, diagnosis and determination of reparative dentine under different root planing, diagnosis of external and internal root bone resorption (furcal resorption), and diagnosis of improvement or deterioration of periapical lesions after endodontic treatment [14]-[16]. Evelise et al. (2011) conducted a study in Brazil on assessing simulated external root bone resorption using direct digital and digital subtraction radiography [17]. The teeth were divided into two groups. DSR was significantly more effective in diagnosing the degenerative lesions of the lingual region greater than $1 \mathrm{~mm}$ compared to digital radiography; yet, there was no statistically significant difference between the two modalities regarding degenerative cavities less than 0.5 $\mathrm{mm}$. Georgios et al. (2011) carried out a comparative study in which they investigated the artificially-induced internal root resorption using digital and digital subtraction radiography [18]. In this study, the sensitivity of digital subtraction radiography in diagnosing cavities was greater than direct digital radiography and smaller-sized cavities $(0.0$ - 6.5) of the middle and apical regions were detected more easily via digital subtraction radiography. The present study investigated the diagnostic effect of digital subtraction radiography in diagnosing in vitro simulated external root resorption.

\section{Methodology}

A total of 20 intact single-rooted premolar teeth were selected. Then, 100 images were recorded for DSR, and 100 for direct digital radiography (DDR). This was an analytic applied study conducted in vitro on 20 human intact single-rooted extracted premolar teeth. The samples were irrigated in water and sterilized in $0.5 \%$ hypochlorite solution for one week and then kept in NSS till the time of the study. To immobilize the teeth in their 
locations, dry human mandible and XCP film-holder were used (Figure 1). A Potty impression was made of the dry mandible and XCP REDICTIVE Using this film-holder, both the location of the tooth and the distance between the tube and the tooth was kept constant during serial exposures at $10 \mathrm{~cm}$. The teeth were then numbered and wax was used to immobilize the teeth in the socket (Figure 1). This was done to maintain the exact geometry of images and the repeatability of radiographs. To make sure that the X-ray tube does not move during the procedure, a hand-made piece of wood was used that contained a circle with a diameter the size of the tube tip on one end. The tube tip was led to this circle during imaging to avoid the sudden movement of the tube. Subsequently, the teeth were placed in the sockets and exposure to $\mathrm{X}$-ray was done under the conditions of $\mathrm{KVp}=$ $63, \mathrm{~mA}=8$, and $\mathrm{T}=0.08$ with the periapical radiographer (Soredex, Helsinki, Finland) using the parallel method at the horizontal angle of $0^{\circ}$ (Figure 2). The sensor used was charged coupled device (CCD) (Soredex Digora Tato, Helsinki, Finland) which was attached to an analog-to-digital convertor with a cable. Thus, after exposure was done, the image appeared on the monitor of the computer rapidly. The acquired images were saved on the computer using the Scanora 4.3.1 software (Soredex, Helsinki, Finland). The 20 selected teeth were divided into two groups of 10. For the first group, the artificially-induced external bone resorption was created with the full tips of 4 round burs (Tizkavan, Iran) of $1 / 4$ (equal to $0.5 \mathrm{~mm}$ ), 1 (equal to $0.8 \mathrm{~mm}$ ), 2 (equal to 1 $\mathrm{mm}$ ), and 3 (equal to $1.2 \mathrm{~mm}$ ) in the $1 / 3$ coronal aspect of the proximal region of the root in the mesial or distal aspect. Following the designing of each cavity, a secondary image was obtained respectively, i.e., an artificial degeneration or resorption was created first in the $1 / 3$ coronal area of the root with the round bur no. 1/4, and then a secondary image was obtained. Next, the depth of the cavity increased using greater bur sizes up to 1 (equal to $0.8 \mathrm{~mm}$ ) and again a secondary image was recorded. This procedure continued up to bur no. 3 (equal to $1.2 \mathrm{~mm}$ ). In the same way, for the second group, first a primary digital radiograph was obtained. Then, the round burs no. $1 / 4,1,2$, and 3 were sequentially used in four stages of increasing cavity diameter in the $1 / 3$ apical region of the root on the lingual aspect. In each stage, a secondary image was acquired and saved using Scanora 4.3.1. To acquire digital subtraction images, Photoshop CS4 (version 11) was used. To do so, it subtracted the pixel value of

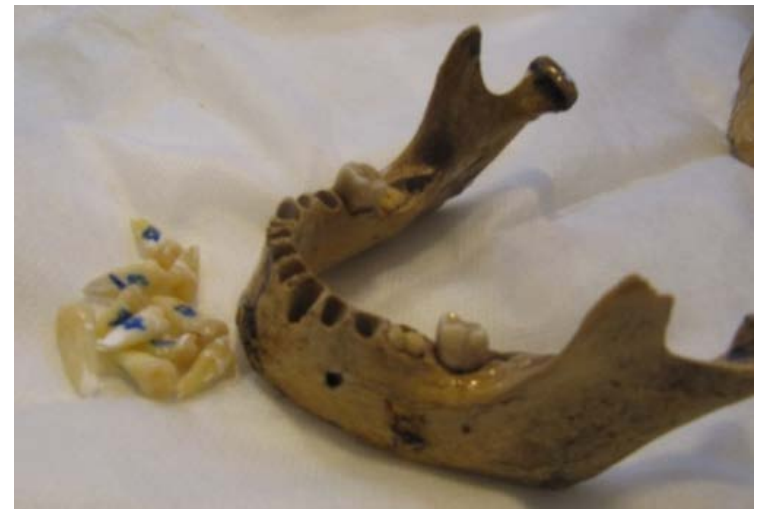

Figure 1. Samples of numbered teeth.

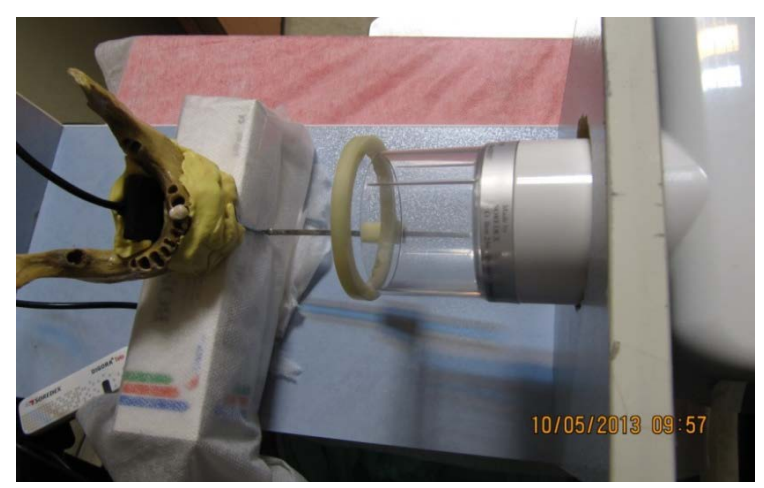

Figure 2. Method of tooth placement in the mandibular socket and X-ray tube adjustment. 
each primary image from its corresponding pixel value of the secondary image. The subtraction of pixels which were the same, produced a grey background and the applied changes were demonstrated in this grey background. In this way, the digital subtraction images were obtained (Figure 3). On the whole, five images were obtained for each tooth. " 1 ” related to the primary digital radiograph and " 4 " related to the sequence of the cavity designings. 20 primary digital radiographs, 100 secondary digital radiographs, and 100 digital subtraction radiographs were obtained for the 20 selected teeth. All images were coded and recorded in a form and the images (with resorption and without resorption) were integrated.

The pairs of primary and secondary radiographs of each tooth were randomly numbered and presented to an observer in a power point file. The pairs of digital subtraction radiographs were also randomly numbered and presented to the interpreter. The interpreters were three maxillofacial radiologists who were aware of the methodology of the research, yet they were blind to the presence or absence of both resorptions and their sites. The data were collected and controlled in SPSS 17 and the required tables and indices were prepared. To analyze the data, Fisher Exact Test, Chi-square Test, Z-test, and Kappa Test were used.

\section{Results}

Observation of cavities with varying depths produced by burs was considered as the gold standard in this study which investigated the diagnostic value of digital subtraction radiography in diagnosing external simulated root bone resorption in the apical and 1/3 coronal regions. The correlation between observed radiographs and the gold standard results was analyzed using Kappa Test. Z-test was used to compare the correlation among various indices. The sensitivity of external root resorption in digital radiography subtraction was known to be $40 \%$, $80 \%$, $90 \%$, and $100 \%$, respectively, based on lesion diameter in the coronal region. The specificity and positive predictive value for all cavities was $100 \%$. Negative predictive value was calculated to be $58.8 \%, 90 \%$, 100\%, and $90.9 \%$, respectively and accuracy of lesion diagnosis was 65\%, 95\%, 100\%, and 95\%, respectively. In the second group, external root resorption was performed using the full tip of the round burs no. 1/4, 1, 2, and 3 in the $1 / 3$ apical region of the root in the lingual aspect. The sensitivity of external root resorption in digital subtraction radiography in terms of lesion diameter in the apical region was 30\%, 50\%, 100\%, and 100\%, respectively, and specificity and and positive predictive value for all cavities of this region was $100 \%$. The negative predictive value was 58.8\%, 66.7\%, 100\%, and 100\%, respectively, and accuracy was 65\%, 75\%, 100\%, and $100 \%$, respectively.

The sensitivity of external root resorption in direct digital radiography in terms of lesion diameter in the apical region was $40 \%, 70 \%, 80 \%$, and $90 \%$, respectively. Specificity of all cavities was $90 \%$ in this region. Positive predictive value was $80 \%, 87.5 \%, 88.9 \%$, and $90.9 \%$, respectively, and negative predictive value was $60 \%$, $75 \%$, $81.8 \%$, and $100 \%$, respectively. Also, accuracy of lesion diagnosis was $65 \%$, $80 \%$, $85 \%$, and $95 \%$, respectively. Based on the results given in Table 1, the sensitivity of DDS was slightly higher than DSR in diagnosing 0.5 mm cavities of the apical region, yet, both methods had low sensitivity (Sen. $=30 \%)$. Based on the results given in Table 2, the sensitivity of both methods of radiography was acceptable. The rate of sensitivity of DDR in both apical and coronal cavities was higher than DSR. Based on Table 3, the sensitivity of DSR in the apical region was higher than DDR, though this difference was not statistically significant $(\mathrm{P}>0.05)$. Table 4 reveals

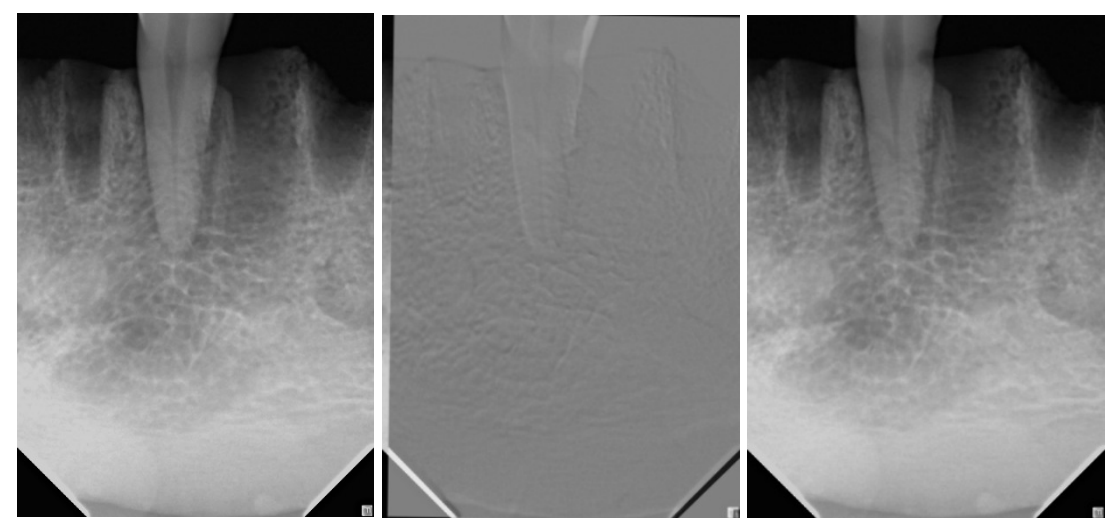

Figure 3. Samples of the obtained DSR and DDR images. 
N. M. Goorabjavari et al.

Table 1. Frequency of correct responses in diagnosing external root resorption of $0.5 \mathrm{~mm}$ cavities in terms of type of radiography and the site of external resorption.

\begin{tabular}{|c|c|c|c|c|c|c|c|}
\hline $\begin{array}{c}\text { Type of } \\
\text { Radiography }\end{array}$ & Lesion Site & Gold & + & - & Total & Kappa & P-value \\
\hline \multirow{6}{*}{$\begin{array}{c}\text { Digital } \\
\text { Subtraction }\end{array}$} & \multirow{3}{*}{ Apical } & + & 3 & 0 & 3 & \multirow{3}{*}{0.3} & \multirow{3}{*}{0.06} \\
\hline & & - & 7 & 10 & 17 & & \\
\hline & & Total & 10 & 10 & 20 & & \\
\hline & \multirow{3}{*}{ Coronal } & + & 4 & 0 & 4 & \multirow{3}{*}{0.4} & \multirow{3}{*}{0.25} \\
\hline & & - & 6 & 10 & 16 & & \\
\hline & & Total & 10 & 10 & 20 & & \\
\hline \multirow{6}{*}{$\begin{array}{l}\text { Direct } \\
\text { Digital }\end{array}$} & \multirow{3}{*}{ Apical } & + & 4 & 1 & 5 & \multirow{3}{*}{0.3} & \multirow{3}{*}{0.121} \\
\hline & & - & 6 & 9 & 15 & & \\
\hline & & Total & 10 & 10 & 20 & & \\
\hline & \multirow{3}{*}{ Coronal } & + & 3 & 0 & 3 & \multirow{3}{*}{0.3} & \multirow{3}{*}{0.06} \\
\hline & & - & 7 & 10 & 17 & & \\
\hline & & Total & 10 & 10 & 20 & & \\
\hline \multicolumn{8}{|c|}{ Chi-square } \\
\hline \multicolumn{2}{|c|}{ Diagnostic Indices } & Direct Digital/Coronal & \multicolumn{2}{|c|}{$\begin{array}{c}\text { Digital Subtraction/ } \\
\text { Coronal }\end{array}$} & Direct Digital/Apical & \multicolumn{2}{|r|}{$\begin{array}{c}\text { Digital Subtraction } \\
\text { Apical }\end{array}$} \\
\hline \multicolumn{2}{|c|}{ Sensitivity } & $30 \%$ & \multicolumn{2}{|c|}{$40 \%$} & $40 \%$ & \multicolumn{2}{|r|}{$30 \%$} \\
\hline \multicolumn{2}{|c|}{ Specificity } & $100 \%$ & \multicolumn{2}{|c|}{$100 \%$} & $90 \%$ & \multicolumn{2}{|r|}{$100 \%$} \\
\hline \multicolumn{2}{|c|}{ PPV } & $100 \%$ & \multicolumn{2}{|c|}{$100 \%$} & $80 \%$ & \multicolumn{2}{|r|}{$100 \%$} \\
\hline \multicolumn{2}{|c|}{$\mathrm{NPV}$} & $58.8 \%$ & \multicolumn{2}{|c|}{$63.5 \%$} & $60 \%$ & \multicolumn{2}{|r|}{$58.8 \%$} \\
\hline \multicolumn{2}{|c|}{ Accuracy } & $65 \%$ & \multicolumn{2}{|c|}{$70 \%$} & $65 \%$ & \multicolumn{2}{|r|}{$65 \%$} \\
\hline
\end{tabular}

Table 2. Frequency of correct responses in diagnosing external root resorption of $0.8 \mathrm{~mm}$ cavities in terms of type of radiography and the site of external resorption.

\begin{tabular}{|c|c|c|c|c|c|c|c|}
\hline $\begin{array}{c}\text { Type of } \\
\text { Radiography }\end{array}$ & Lesion Site & Gold & + & - & Total & Карра & P-value \\
\hline \multirow{6}{*}{$\begin{array}{c}\text { Digital } \\
\text { Subtraction }\end{array}$} & \multirow{3}{*}{ Apical } & + & 5 & 0 & 5 & \multirow{3}{*}{0.5} & \multirow{3}{*}{0.01} \\
\hline & & - & 5 & 10 & 15 & & \\
\hline & & Total & 10 & 10 & 20 & & \\
\hline & \multirow{3}{*}{ Coronal } & + & 8 & 0 & 8 & \multirow{3}{*}{0.8} & \multirow{3}{*}{0.00} \\
\hline & & - & 2 & 10 & 12 & & \\
\hline & & Total & 10 & 10 & 20 & & \\
\hline \multirow{6}{*}{$\begin{array}{l}\text { Direct } \\
\text { Digital }\end{array}$} & \multirow{3}{*}{ Apical } & + & 7 & 1 & 8 & \multirow{3}{*}{0.6} & \multirow{3}{*}{0.006} \\
\hline & & - & 3 & 9 & 12 & & \\
\hline & & Total & 10 & 10 & 20 & & \\
\hline & \multirow{3}{*}{ Coronal } & + & 9 & 0 & 9 & \multirow{3}{*}{0.9} & \multirow{3}{*}{0.000} \\
\hline & & - & 1 & 10 & 11 & & \\
\hline & & Total & 10 & 10 & 20 & & \\
\hline \multicolumn{2}{|c|}{ Diagnostic Indices } & Direct Digital/Coronal & \multicolumn{2}{|c|}{$\begin{array}{c}\text { Digital Subtraction/ } \\
\text { Coronal }\end{array}$} & Direct Digital/Apical & \multicolumn{2}{|c|}{$\begin{array}{c}\text { Digital Subtraction/ } \\
\text { Apical }\end{array}$} \\
\hline \multicolumn{2}{|c|}{ Sensitivity } & $90 \%$ & \multicolumn{2}{|c|}{$80 \%$} & $70 \%$ & \multicolumn{2}{|c|}{$50 \%$} \\
\hline \multicolumn{2}{|c|}{ Specificity } & $100 \%$ & \multicolumn{2}{|c|}{$100 \%$} & $90 \%$ & \multicolumn{2}{|c|}{$100 \%$} \\
\hline \multicolumn{2}{|c|}{ PPV } & $100 \%$ & \multicolumn{2}{|c|}{$100 \%$} & $87.5 \%$ & \multicolumn{2}{|c|}{$100 \%$} \\
\hline \multicolumn{2}{|c|}{ NPV } & $90 \%$ & \multicolumn{2}{|c|}{$83.3 \%$} & $75 \%$ & \multicolumn{2}{|c|}{$66.7 \%$} \\
\hline \multicolumn{2}{|c|}{ Accuracy } & $95 \%$ & \multicolumn{2}{|c|}{$90 \%$} & $80 \%$ & \multicolumn{2}{|c|}{$75 \%$} \\
\hline
\end{tabular}


Table 3. Frequency of correct responses in diagnosing external root resorption of $1 \mathrm{~mm}$ cavities in terms of type of radiography and the site of external resorption.

\begin{tabular}{|c|c|c|c|c|c|c|c|}
\hline $\begin{array}{c}\text { Type of } \\
\text { Radiography }\end{array}$ & Lesion Site & Gold & + & - & Total & Карра & P-value \\
\hline \multirow{6}{*}{$\begin{array}{c}\text { Digital } \\
\text { Subtraction }\end{array}$} & \multirow{3}{*}{ Apical } & + & 10 & 0 & 10 & \multirow{3}{*}{1} & \multirow{3}{*}{0.00} \\
\hline & & - & 0 & 10 & 10 & & \\
\hline & & Total & 10 & 10 & 20 & & \\
\hline & \multirow{3}{*}{ Coronal } & + & 9 & 0 & 9 & \multirow{3}{*}{0.9} & \multirow{3}{*}{0.00} \\
\hline & & - & 1 & 10 & 11 & & \\
\hline & & Total & 10 & 10 & 20 & & \\
\hline \multirow{6}{*}{$\begin{array}{l}\text { Direct } \\
\text { Digital }\end{array}$} & \multirow{3}{*}{ Apical } & + & 8 & 1 & 9 & \multirow{3}{*}{0.7} & \multirow{3}{*}{0.02} \\
\hline & & - & 2 & 9 & 11 & & \\
\hline & & Total & 10 & 10 & 20 & & \\
\hline & \multirow{3}{*}{ Coronal } & + & 10 & 0 & 10 & \multirow{3}{*}{1} & \multirow{3}{*}{0.000} \\
\hline & & - & 0 & 10 & 10 & & \\
\hline & & Total & 10 & 10 & 20 & & \\
\hline \multicolumn{2}{|c|}{ Diagnostic Indices } & Direct Digital/Coronal & \multicolumn{2}{|c|}{$\begin{array}{c}\text { Digital Subtraction/ } \\
\text { Coronal }\end{array}$} & Direct Digital/Apical & \multicolumn{2}{|c|}{$\begin{array}{c}\text { Digital Subtraction/ } \\
\text { Apical }\end{array}$} \\
\hline \multicolumn{2}{|c|}{ Sensitivity } & $100 \%$ & \multicolumn{2}{|c|}{$90 \%$} & $80 \%$ & \multicolumn{2}{|c|}{$100 \%$} \\
\hline \multicolumn{2}{|c|}{ Specificity } & $100 \%$ & \multicolumn{2}{|c|}{$100 \%$} & $90 \%$ & \multicolumn{2}{|c|}{$100 \%$} \\
\hline \multicolumn{2}{|c|}{ PPV } & $100 \%$ & \multicolumn{2}{|c|}{$100 \%$} & $88.9 \%$ & \multicolumn{2}{|c|}{$100 \%$} \\
\hline \multicolumn{2}{|c|}{ NPV } & $100 \%$ & \multicolumn{2}{|c|}{$90.9 \%$} & $81.8 \%$ & \multicolumn{2}{|c|}{$100 \%$} \\
\hline \multicolumn{2}{|c|}{ Accuracy } & $100 \%$ & \multicolumn{2}{|c|}{$95 \%$} & $85 \%$ & \multicolumn{2}{|c|}{$100 \%$} \\
\hline
\end{tabular}

Table 4. Frequency of correct responses in diagnosing external root resorption of $0.8 \mathrm{~mm}$ cavities in terms of type of radiography and the site of external resorption.

\begin{tabular}{|c|c|c|c|c|c|c|c|}
\hline $\begin{array}{c}\text { Type of } \\
\text { Radiography }\end{array}$ & Lesion Site & Gold & + & - & Total & Kappa & P-value \\
\hline \multirow{6}{*}{$\begin{array}{c}\text { Digital } \\
\text { Subtraction }\end{array}$} & \multirow{3}{*}{ Apical } & + & 5 & 0 & 5 & \multirow{3}{*}{1} & \multirow{3}{*}{0.000} \\
\hline & & - & 5 & 10 & 15 & & \\
\hline & & Total & 10 & 10 & 20 & & \\
\hline & \multirow{3}{*}{ Coronal } & + & 8 & 0 & 8 & \multirow{3}{*}{1} & \multirow{3}{*}{0.000} \\
\hline & & - & 2 & 10 & 12 & & \\
\hline & & Total & 10 & 10 & 20 & & \\
\hline \multirow{6}{*}{$\begin{array}{l}\text { Direct } \\
\text { Digital }\end{array}$} & \multirow{3}{*}{ Apical } & + & 7 & 1 & 8 & \multirow{3}{*}{0.9} & \multirow{3}{*}{0.000} \\
\hline & & - & 3 & 9 & 12 & & \\
\hline & & Total & 10 & 10 & 20 & & \\
\hline & \multirow{3}{*}{ Coronal } & + & 9 & 0 & 9 & \multirow{3}{*}{0.9} & \multirow{3}{*}{0.000} \\
\hline & & - & 1 & 10 & 11 & & \\
\hline & & Total & 10 & 10 & 20 & & \\
\hline \multicolumn{2}{|c|}{ Diagnostic Indices } & Direct Digital/Coronal & \multicolumn{2}{|c|}{$\begin{array}{c}\text { Digital Subtraction/ } \\
\text { Coronal }\end{array}$} & Direct Digital/Apical & \multicolumn{2}{|c|}{$\begin{array}{c}\text { Digital Subtraction/ } \\
\text { Apical }\end{array}$} \\
\hline \multicolumn{2}{|c|}{ Sensitivity } & $90 \%$ & \multicolumn{2}{|c|}{$90 \%$} & $100 \%$ & \multicolumn{2}{|c|}{$100 \%$} \\
\hline \multicolumn{2}{|c|}{ Specificity } & $100 \%$ & \multicolumn{2}{|c|}{$100 \%$} & $90 \%$ & \multicolumn{2}{|c|}{$100 \%$} \\
\hline \multicolumn{2}{|c|}{ PPV } & $100 \%$ & \multicolumn{2}{|c|}{$100 \%$} & $90.9 \%$ & \multicolumn{2}{|c|}{$100 \%$} \\
\hline \multicolumn{2}{|c|}{ NPV } & $90.9 \%$ & \multicolumn{2}{|c|}{$100 \%$} & $100 \%$ & \multicolumn{2}{|c|}{$100 \%$} \\
\hline \multicolumn{2}{|c|}{ Accuracy } & $95 \%$ & \multicolumn{2}{|c|}{$100 \%$} & $95 \%$ & \multicolumn{2}{|c|}{$100 \%$} \\
\hline
\end{tabular}


that the diagnosis of $1.2 \mathrm{~mm}$ cavities in the apical region, sensitivity indices, and NPV of both DSR and DDR were the same. However, DSR was better in other indices though the difference was not significant $(P>0.05)$. As Table 5 demonstrates it, the Kappa index of both types of radiography shows that the responses are not close to the gold standard in diagnosing the small size of $0.5 \mathrm{~mm}$ cavities, yet, the difference is statistically significant $(\mathrm{P}<0.05)$. Table 6 displays the frequency of correct responses in diagnosing $0.8 \mathrm{~mm}$ cavities using DSR and DDR. As the table shows, the rates of accuracy and sensitivity in diagnosing this cavity were greater compared to $0.5 \mathrm{~mm}$ cavity. Also, the obtained Kappa index is higher indicating that the responses are closer to the gold standard. Table 7 presents the frequency of the observers' correct responses.

Table 5. Frequency of correct responses in diagnosing external root resorption of $0.5 \mathrm{~mm}$ cavities compared to gold standard in both types of radiography.

\begin{tabular}{|c|c|c|c|c|c|c|}
\hline $\begin{array}{c}\text { Type of } \\
\text { Radiography }\end{array}$ & Test & + & - & Total & Kappa & P-value \\
\hline \multirow{3}{*}{$\begin{array}{c}\text { Digital } \\
\text { Subtraction }\end{array}$} & + & 7 & 0 & 7 & \multirow{3}{*}{0.35} & \multirow{3}{*}{0.004} \\
\hline & - & 13 & 20 & 33 & & \\
\hline & Total & 20 & 20 & 40 & & \\
\hline \multirow{3}{*}{ Direct Digital } & + & 7 & 1 & 8 & \multirow{3}{*}{0.30} & \multirow{3}{*}{0.018} \\
\hline & - & 13 & 19 & 32 & & \\
\hline & Total & 20 & 20 & 40 & & \\
\hline \multicolumn{7}{|c|}{ Chi-square } \\
\hline \multicolumn{2}{|c|}{ Diagnostic Indices } & \multicolumn{3}{|c|}{ Direct Digital } & \multicolumn{2}{|c|}{ Subtraction } \\
\hline \multicolumn{2}{|c|}{ Sensitivity } & \multicolumn{3}{|c|}{$35 \%$} & \multicolumn{2}{|c|}{$35 \%$} \\
\hline \multicolumn{2}{|c|}{ Specificity } & \multicolumn{3}{|c|}{$95 \%$} & \multicolumn{2}{|c|}{$100 \%$} \\
\hline \multicolumn{2}{|c|}{ Positive Predictive Value } & \multicolumn{3}{|c|}{$87.5 \%$} & \multicolumn{2}{|c|}{$100 \%$} \\
\hline \multicolumn{2}{|c|}{ Negative Predictive Value } & \multicolumn{3}{|c|}{$59.4 \%$} & \multicolumn{2}{|c|}{$60.7 \%$} \\
\hline \multicolumn{2}{|c|}{ Accuracy } & \multicolumn{3}{|c|}{$65 \%$} & \multicolumn{2}{|c|}{$67.5 \%$} \\
\hline
\end{tabular}

Table 6. Frequency of correct responses in diagnosing external root resorption of $0.8 \mathrm{~mm}$ cavities compared to gold standard in both types of radiography.

\begin{tabular}{|c|c|c|c|c|c|c|}
\hline $\begin{array}{c}\text { Type of } \\
\text { Radiography }\end{array}$ & Test & + & - & Total & Kappa & P-value \\
\hline \multirow{3}{*}{$\begin{array}{c}\text { Digital } \\
\text { Subtraction }\end{array}$} & + & 13 & 0 & 13 & \multirow{3}{*}{0.65} & \multirow{3}{*}{0.000} \\
\hline & - & 7 & 20 & 27 & & \\
\hline & Total & 20 & 20 & 40 & & \\
\hline \multirow{3}{*}{ Direct Digital } & + & 16 & 1 & 17 & \multirow{3}{*}{0.75} & \multirow{3}{*}{0.000} \\
\hline & - & 4 & 19 & 23 & & \\
\hline & Total & 20 & 20 & 40 & & \\
\hline \multicolumn{7}{|c|}{ Chi-square } \\
\hline \multicolumn{2}{|c|}{ Diagnostic Indices } & \multicolumn{3}{|c|}{ Direct Digital } & \multicolumn{2}{|c|}{ Subtraction } \\
\hline \multicolumn{2}{|c|}{ Sensitivity } & \multicolumn{3}{|c|}{$80 \%$} & \multicolumn{2}{|c|}{$65 \%$} \\
\hline \multicolumn{2}{|c|}{ Specificity } & \multicolumn{3}{|c|}{$95 \%$} & \multicolumn{2}{|c|}{$100 \%$} \\
\hline \multicolumn{2}{|c|}{ Positive Predictive Value } & \multicolumn{3}{|c|}{$94.1 \%$} & \multicolumn{2}{|c|}{$100 \%$} \\
\hline \multicolumn{2}{|c|}{ Negative Predictive Value } & \multicolumn{3}{|c|}{$82.6 \%$} & \multicolumn{2}{|c|}{$74.1 \%$} \\
\hline \multicolumn{2}{|c|}{ Accuracy } & \multicolumn{3}{|c|}{$87.5 \%$} & \multicolumn{2}{|c|}{$82.5 \%$} \\
\hline
\end{tabular}


Table 7. Distribution of the correct responses of the observers.

\begin{tabular}{ccc}
\hline $\begin{array}{c}\text { Number of correct responses for } \\
\text { each observer }\end{array}$ & Frequency & Percent \\
\hline 0 & 20 & $10 \%$ \\
1 & 22 & $11 \%$ \\
2 & 27 & $13.5 \%$ \\
3 & 131 & $65.5 \%$ \\
Total & 100 & 200 \\
\hline
\end{tabular}

\section{Discussion}

One of the current problems of dentistry is the early diagnosis of external tooth resorption. Lack of early diagnosis leads to resorption of dental surfaces and reduced tooth maintenance. Regarding the point that the first diagnosis of tooth degeneration is made on the basis of intra-oral film radiographs, the necessity of the use of new and reliable radiological methods in lesion diagnosis is obvious [19]. Today, due to advancements in technology digital radiography competes with conventional radiography. Slight deviations in tooth usually escape from the attention of dentists due to low dental density or overlap of structure and the surrounding tissues in radiography film. Yet, digital subtraction radiography can reveal mineral reduction or resorption by 1\% - 5\% [6] [13] [20]. The study by Holmes et al. [21] entitled: "Diagnosis of Internal Root Resorption Using Conventional and Digital Subtraction Radiography” demonstrated that the lesions created with a medium-size bur (010, 012) in the coronal region were detectable using conventional film radiography, yet, the apical lesions were detectable only if they were created with large-size burs $(014,016)$. The overall accuracy of subtraction images was superior only in coronal lesions compared to conventional film radiography and the difference was significant. In the present study, the sensitivity and accuracy of digital subtraction radiography in the $0.5 \mathrm{~mm}$ cavity of the coronal region was better than that of direct digital radiography, a finding which is consistent with Holmes' study. One of the strong points of the present study is the comparison of DDR with DSR since the images were consistent regarding image contrast and pixel resolution, whereas conventional radiographs were used in Holmes' study. The radiographs functioned better in diagnosing coronal lesions than apical lesions in both this study and Holmes' study. It appears that details are more vividly observable in the mesiodistal aspects of the coronal region of the root compared to middle and apical regions due to greater width. In the study by Hintz et al. [11] entitled: "Study of Degenerative Cavities on the Root Using Digital Subtraction Radiography", although there were more small cavities observed using DSR, yet their number did not increase on the whole compared to conventional radiography. In this study, except for $0.8 \mathrm{~mm}$ cavity, DSR showed greater accuracy in $0.5,1$, and 1.2 mm cavities compared to DDR which was not statistically significant contrasting the results of Hintz. Of course, Hintz’ study like Holmes', used conventional radiography for comparison with DSR. In another study by Qaffari et al. [22], the accuracy rate of DSR in diagnosing artificial external root resorption was determined. It showed that DSR had greater sensitivity in diagnosing small degenerative lesions of proximal and facial surfaces compared to DDR, yet, sensitivity was similar for large lesions.

In the present study, DSR had the same sensitivity as DDR in diagnosing small lesions and the sensitivity rate of DSR was greater in diagnosing large lesions contrasting Qaffari’s findings. Qaffari's study used only 10 teeth which is smaller in number compared to the present study. The greater number of samples is one of the strong points of the present study. The study by Varshowsaz et al. [23] examined the accuracy of DSR in diagnosing dental demineralized lesions and found that this modality had greater accuracy in diagnosing early lesions while it had a similar accuracy value for moderate caries compared to DDR. In the present study, DSR showed good accuracy in diagnosing both small and large lesions, yet its accuracy rate was not significantly different from DDR. Another study by Evelise et al. [17] examined the artificially-induced external root resorption using DDR and DSR. They found that DSR was significantly more effective than DDR in diagnosing degenerative lesions of lingual regions greater than $1 \mathrm{~mm}$; however, there was no significant difference between the two methods in degenerative cavities smaller than $0.5 \mathrm{~mm}$. In Evelise's study, both modalities of radiography did not have any good accuracy in diagnosing small $0.5 \mathrm{~mm}$ cavities, yet the methods showed an acceptable accuracy in diagnosing the small $0.5 \mathrm{~mm}$ cavity contrasting Evelise's results. In Evelise's study, the observers or interpreters had 
greater agreement on digital subtraction studies compared to DDR images which is consistent with Evelise's findings. One of the strong points of Evelise's study is the large sample size exceeding that of the study above. Another study by Georgios et al. assessed the artificially simulated internal root resorption using DDR and DSR and found that the sensitivity of DSR was generally greater in diagnosing cavities compared to DDR and that small-sized cavities $(0.5$ and $0.6 \mathrm{~mm})$ in the middle and apical regions of tooth root were more easily detected via DSR. In the present study, the sensitivity of DSR and DDR was the same in diagnosing $0.5 \mathrm{~mm}$ cavities. Also, the sensitivity of DSR was slightly greater in diagnosing $1 \mathrm{~mm}$ and $1.2 \mathrm{~mm}$ cavities compared to DDR. Furthermore, the coronal region cavities of the root were more easily detectable with DSR and DDR contrasting Georgios' findings. Generally speaking, various factors are at work in observing and interpreting radiographic films including the imaging system such as conventional or digital radiography, observation conditions, image manipulation, type, dimensions, and site of carious lesions [24] [25]. However, the more important issue is the experience of the observer or interpreter in the application of digital images and specifically the related software [25]. It seems that a person with a long experience in using radiographic films for diagnosis enjoys greater diagnostic power in diagnosing digital radiographic lesions [26].

\section{Conclusion}

The rate of sensitivity for diagnosing small $0.5 \mathrm{~mm}$ cavities was low with both methods of radiography. Both modalities of DSR and DDR worked better in the diagnosis of coronal region cavities. On the whole, the performance of DSR was superior to DDR in diagnosing all cavities except $0.8 \mathrm{~mm}$ cavities. The interpreters had better performance in diagnosing external root resorption with DSR compared to DDR. In sum, the results obtained with DSR were not significantly different from DDR.

\section{References}

[1] Bakland, L.K. (1992) Root Resorption. Dental Clinics of North America, 36, 491-507.

[2] Freitas, A., Rosa, J.E. and Souza, I.F. (2000) Radiologia Odontologica. 5th Edition, Artes Medicas, Sao Paulo, 157.

[3] Seltzre, S. and Kranser, P. (1998) Endodotology; Biologic Considerations in Endodontic Procedures. 2nd Edition, Lea and Sibiger, Philadelphia, 170-190, 527-543.

[4] Cohen, S. and Hargreves, K. (2006) Pathway of the Pulp. 9th Edition, Mosby Co., St. Luis, So4-47, 704-727.

[5] White, S.C. and Pharoah, M.J. (2014) Oral Radiology: Principles and Interpretation, 7th Edition, Elsevier, Health Sciences Division, Amsterdam, 41-63.

[6] Lozano, A., Fomer, L. and Liena, C. (2002) In Vitro Comparison of Root Canal Measurements with Conventional and Digital Radiography. International Endodontic Journal, 35, 542-550.

[7] Neena, I.E., Ananthraj, A., Praveen, P., Karthik, V. and Rani, P. (2011) Comparison of Digital Radiography and Apex Locator with the Conventional Method in Root Length Determination of Primary Teeth. Journal of Indian Society of Pedodontics and Preventive Dentistry, 29, 300-304. http://dx.doi.org/10.4103/0970-4388.86371

[8] Kamburoglu, K., TsesisI, K.A. and Kaffe, I. (2008) Diagnosis of Arthficially Induced External Root resoption Using Conventional Intraoral Film Radiography, CCD and PSP an ex Vivo Study. Oral Surg med Sral Pathol Pral Radiol Endod, 100, 885-891.

[9] Kravitz, L.H., Tyndull, D.A., Bagnell, C.P. and Dove, S.B. (1992) Assessment of External Root Resorption Using Digital Subtraction Radiography. Journal of Endodontics, 18, 275-284. http://dx.doi.org/10.1016/S0099-2399(06)80954-4

[10] Reddy, M.S. and Jeffcoat, M.K. (1993) Digital Subtraction Radiography. Dental Clinics of North America, 37, 553565.

[11] Hintze, H., Wenzel, A., Andreasen, F.M. and Swevin, I. (1992) Digital Subtraction Radiography for Assessment of Simulated Root Resorption Cavities. Performance of Conventional and Reverse Contrast Modes. Endodontics \& Dental Traumatology, 8, 149-154. http://dx.doi.org/10.1111/j.1600-9657.1992.tb00234.x

[12] Ohki, M., Okano, T. and Yamada, N. (1988) A Contrast-Correction Method for Digital Subtraction Radiography. Journal of Periodontal Research, 23, 277-280. http://dx.doi.org/10.1111/j.1600-0765.1988.tb01372.x

[13] Wenzel, A., Anthonisen, P.N. and Juun, M.B. (2000) Reproducibility in the Assessment of Caries Lesion Behavior: A Comparison between Conventional Film and Subtraction Radiography. Caries Research, 34, 214-218. http://dx.doi.org/10.1159/000016593

[14] Jeffcoat, M.K., Reddy, M.S., Page, R., Wannawisute, A., Waite, P., Palcanis, K., et al. (1991) Use of Digital Radiography to Demonstrate the Potential of Naproxen as an Adjust in the Treatment of Rapidly Progressive Periodontitis. 
Journal of Periodontal Research, 26, 415-421. http://dx.doi.org/10.1111/j.1600-0765.1991.tb01731.x

[15] Wenzel, A. and Halse, A. (1992) Digital Subtraction Radiography after Stannous Fluoride Treatment for Occlusal Caries Diagnosis. Oral Surgery, Oral Medicine, Oral Pathology, 74, 824-828. http://dx.doi.org/10.1016/0030-4220(92)90416-N

[16] Grondahl, H.G., Grondahl, K. and Webber, R.L. (1983) A Digital Subtraction Technique for Dental Radiography. Oral Surgery, Oral Medicine, Oral Pathology, 55, 96-102. http://dx.doi.org/10.1016/0030-4220(83)90314-6

[17] Ono, E., Filho, E.M., Leite, H.F., Oshiro Tanaka, J.L., De Moraes, M.E.L. and De Melo Castilho, J.C. (2011) Evaluation of Simulated External Root Resorption with Digital Radiography and Digital Subtraction Radiography. American Journal of Orthodontics and Dentofacial Orthopedics, 139, 324-333. http://dx.doi.org/10.1016/j.ajodo.2009.03.046

[18] Georgios, S., Georgios, M. and Kleoniki, L. (2011) Assessment of Simulated Internal Resorption Cavities Using Digital and Digital Subtraction Radiography: A Comparative Study. Dental Traumatology, 27, 344-349. http://dx.doi.org/10.1111/j.1600-9657.2011.01020.x

[19] Borg, E., Kallqvist, A. and Grondahl, H.G. (1998) Film and Digital Radiography for Detection of Simulated Root Resorption Cavities. Oral Surgery, Oral Medicine, Oral Pathology, Oral Radiology, and Endodontology, 86, 110-114. http://dx.doi.org/10.1016/S1079-2104(98)90159-7

[20] Halse, A., Espelid, T., Veit, A.B. and White, S.C. (2005) Detection of Mineral Resorption in Approximal Enamel by Subtraction Radiography. Oral Surgery, Oral Medicine, Oral Pathology, 77, 177-132.

[21] Holmes, J.P., Gulabivala, K. and Van Stelt, P.F. (2001) Detection of Simulated Internal Tooth Resorption Using Conventional Radiography and Subtraction Imaging. Dentomaxillofacial Radiology, 30, 249-254. http://dx.doi.org/10.1038/sj.dmfr.4600626

[22] Qaffari, R. and Keshavarzi, M. (2008) Evaluation of Accuracy of Digital Subtraction Radiography in Diagnosing in Vitro Artificially-induced External Root Rersorption. Journal of Isfahan Dental School, 4, 141-148.

[23] Varshowsaz, M. and Ghattari, R. (2007) Evaluation of the Accuracy of Digital Subtraction Radiography in the Detection of Dental Demineralization (in Vitro). Journal of Dental School, 22, 332-340. (Persian)

[24] Uprichard, K.K., Potter, B.J., Russell, C.M., Schafer, T.E., Adair, S. and Weller, R.N. (2000) Comparison of Direct Digital and Conventional Radiography for the Detection of Proximal Surface Caries in the Mixed Dentition. Pediatric Dentistry, 22, 9-15.

[25] Alkurt, M.T., Peker, I., Bala, O. and Altunkaynak, B. (2007) In Vitro Comparison of Four Different Dental X-Ray Films and Direct Digital Radiography for Proximal Caries Detection. Operative Dentistry, 32, 504-509. http://dx.doi.org/10.2341/06-148

[26] Bernier-Rodriguez, J.A., Sidow, S.J., Joyce, A.P., McNally, K. and McPherson, J.C. (2008) Radiographic Interpretation of Experimental Lesions in Radicular Tooth Structure of Human Maxillary Anterior Teeth. Journal of Endodontics, 34, 1466-1469. http://dx.doi.org/10.1016/j.joen.2008.09.009

\section{Abbreviations}

DDR: Direct Digital Radiography

DSR: Digital Subtraction Radiography 